\title{
Evaluation the Effect of Microwave Radiation on Gram Positive and Negative Bacteria
}

\author{
Esam Bashir Yahya ${ }^{1,}{ }^{*}$,Ali M Almashgab ${ }^{2}$, Muhanad Abdullah Abdulsamad ${ }^{3}$, \\ Abdulmutalib Alabeed Allaq ${ }^{4}$, Amaal Mohammed Alqadhi', Fatima M Garatem ${ }^{1}$, Sara \\ S Aljundi 1. \\ ${ }^{1}$ Dept. of Microbiology, Faculty of Science, Al Asmarya Islamic University, Zliten, Libya \\ ${ }^{2}$ Dept. of Zoology, Faculty of Science, Al Asmarya Islamic University, Zliten, Libya \\ ${ }^{3}$ Dept. of Molecular Biology, Faculty of Science, Sabratha University, Sabratha, Libya \\ ${ }^{4}$ Faculty of applied science, Universiti Teknologi MARA, Shah Alam, Malaysia
}

\begin{tabular}{llllll}
\hline Received: 27.01.2021 $\quad$ Accepted: 03.03.2021 $\quad$ • & Published: 30.04.2021 & • Final Version: 30.04 .2021
\end{tabular}

\begin{abstract}
Using microwave oven nowadays has become necessary due to the need for speed in our daily activities. It is widely used in hating, thawing, and even cooking of food. It has been also used in sterilization and decontamination of food from microorganisms. This study aimed to evaluate thermal and non-thermal effect of a regular house holding microwave oven on Staphylococcus aureus and Escherichia coli. Bacterial suspension is exposed to microwave radiations in different strength and durations and compared to unexposed cultures. During microwave treatment, non-thermal effect is evaluated by putting the suspension crushed ice. The results indicate that the viability of both gram positive and negative was highly reduced with thermal effect of microwave radiations, leading to complete inactivation at three minutes. Non-thermal microwave radiations were also able to cause change in the microbial viability of both tested organisms on at least two-exposure occasion. The evaluation of antibiotic susceptibility before and after microwave radiations treatment indicate that antibiotic resistance was highly increased to tested antibiotics specially after three-minute exposure, except for Staphylococcus aureus to Amoxicillin, which became more sensitive. Microwave radiations reported to have a strong activity in eliminating the number of microbes but, it may have an important role in development of antibiotic resistance that should not be ignored.
\end{abstract}

Keywords: microwave radiation, thermal effects, non-thermal effects, mutagen; bacterial variability.

\footnotetext{
* Corresponding Author: essam912013@gmail.com
} 


\section{Introduction}

Microwave is defined as electromagnetic non-ionizing waves ranging from 0.3 to 300 gigahertz (GHz) frequencies (Cohen \& Wald, 2016). The thermal and/or non-thermal effect of microwave irradiation could cause the abnormal permeability of bacterial cell membrane and the degeneration of protein, resulting in bacterial metabolic abnormalities and irreversible damage of bacteria (Qiao, Ying, Singer, \& Zhu, 2018; E. B. Yahya et al., 2020). It could also cause antibiotic resistant mutations (E. B. Yahya, Alhawari, Amhimmid, AbuAeshah, \& Saada, 2018). However, huge number of pathogenic and non-pathogenic bacteria is frequently exposed to microwave radiations (MR) with food in the houses, cafes, and restaurants. Depending on the strength and frequency of radiation, MR may affect the viability of microorganisms. Therefore, when irradiating living organisms, microwaves produce two types of effect, thermal and non-thermal. Thermal effects are the consequences of absorption of MR by cell molecules. It was suggested that killing microorganism is achieved by thermal effect of microwave exposure (Kang \& Kato, 2014; Wilbur \& Al Tawengi, 2016). On the other hand, Alharbi et al., 2016; Banik, Bandyopadhyay, \& Ganguly, (2003) showed that the effect of the nonthermal effect of MR was variable. Biagi et al., (2016) concluded that MR heating has an extent destructive ability to bacterial cells than any other heating method with similar temperature. Alharbi et al., (2016) study on different biological models reported that the effect of MR depends on the type, frequency, duration, and organism model.

Many scientific papers have been published about the effect of MR on microorganisms, such as bacterial motility and biofilm formation (I. H. Said-Salman, F. A. Jebaii, H. H. Yusef, \& M. E. Moustafa, 2019); the amount of toxin and exopolysaccharide production (Ma et al., 2019); bacterial virulence (Patel et al., 2019); and bacterial level of growth and metabolism (Mazinani, 2019). In this study, the researchers aimed to study and evaluate the role of time of exposure and the intensity of each of microwave thermal and nonthermal radiation on the survival and antibiotic resistance mutagenesis of $S$. aureus and E. coli exposed to MR compared to unexposed cells.

\section{Material and Method Standardization of Bacterial Cells}

Pathogenic stains including Staphylococcus aureus and Escherichia coli were isolated from diabetic wound from Zliten teaching hospital, and biochemically identified in microbiology laboratory in AlAsmarya Islamic University. Spectrophotometer was used to adjust a 0.5 MacFarland standard from the two bacterial cells using $0.85 \%$ (w/v) sterile saline solution and bacterial colonies in logarithmic phase. The number of bacterial cells in suspension was confirmed by direct counting using haemocytometer (E. Yahya \& Abdulsamad, 2020).

\subsection{Evaluation of Microwave Radiation Effect}

Three exposure times 1, 2 and 3 minutes, and two percent exposure power (40 and 80\%) by using a household microwave oven (Hommer) with a wavelength of 2,450 MegaHertZ. $10 \mathrm{ml}$ of bacterial suspension were put in tube. The tube was placed in an empty glass placed in the center of the microwave oven and exposed to MR. For determination of non-thermal effect, the elevation of temperature (thermal effect) of MR was avoided by putting the inoculum in ice during MR treatment. Whatever alterations in bacterial variability and/or mutagenesis that have been observed are most likely attributed to MR specific effects (Non-thermal effects). However, untreated samples were used 
as a control group of each tested microorganisms. After MR exposure, $1 \mathrm{ml}$ was aseptically taken from each tube, and serial dilution was done to count the CFU number.

\subsection{Evaluation of Mutagenic Effect of the Microwave Radiation}

Mutagenic effect was determined by evaluating the sensitivity of bacteria before and after exposure to MR to four antibiotics by disk diffusion method. After the period of incubation, the zone of inhibition was measured with a caliper in millimeter. Studies were performed in duplicate, and mean value was calculated.

\section{Results}

The results of thermal and non-thermal effect of MR presented in Table 1. Gram negative E. coli were more sensitive to both thermal and non-thermal MR power than Gram positive $S$. aureus. The temperature of bacterial suspension after MR treatment was measured in both thermal $(75,93$ and $94{ }^{\circ} \mathrm{C}$ for 1,2 and 3 min respectively) and non-thermal $\left(23,28\right.$ and $41{ }^{\circ} \mathrm{C}$ for 1,2 and 3 min respectively) microwave treatment. The quantity of water become noticeably reduced (50\%) in the 3 min exposure of thermal effect treatment.

Table 1. Viable count of bacteria after exposure to Microwave radiation for different durations (CFU)

\begin{tabular}{|c|c|c|c|c|c|c|}
\hline \multicolumn{7}{|c|}{ A. S. aureus } \\
\hline & \multicolumn{2}{|c|}{$1 \mathrm{~min}$} & \multicolumn{2}{|c|}{$2 \min$} & \multicolumn{2}{|c|}{$3 \mathrm{~min}$} \\
\hline & $40 \%$ & $80 \%$ & $40 \%$ & $80 \%$ & $40 \%$ & $80 \%$ \\
\hline $\begin{array}{l}\text { Thermal } \\
\text { effect }\end{array}$ & 26 & 130 & 88 & 24 & 5 & 3 \\
\hline $\begin{array}{l}\text { Non- } \\
\text { thermal } \\
\text { effect }\end{array}$ & un & un & un & 192 & 124 & 112 \\
\hline \multicolumn{7}{|c|}{ B. E. coli } \\
\hline & \multicolumn{2}{|c|}{$1 \mathrm{~min}$} & \multicolumn{2}{|c|}{$2 \mathrm{~min}$} & \multicolumn{2}{|c|}{$3 \mathrm{~min}$} \\
\hline & $40 \%$ & $80 \%$ & $40 \%$ & $80 \%$ & $40 \%$ & $80 \%$ \\
\hline $\begin{array}{l}\text { Thermal } \\
\text { effect }\end{array}$ & 19 & 28 & 3 & 0 & 0 & 2 \\
\hline $\begin{array}{l}\text { Non- } \\
\text { thermal } \\
\text { effect }\end{array}$ & un & un & un & un & 160 & 17 \\
\hline
\end{tabular}

un $=$ uncountable number of colonies $(>200 \mathrm{cfu})$

Evaluation of antibiotics sensitivity for both the wide type strain (Control) and the survival cell from 2- and 3-min exposure was presented in table 2 and fig. 1 . The sensitivity of bacteria to most of tested antibiotics decreased specially after 3 min exposure, except for $S$. aureus to Amoxicillin, which became more sensitive. 
Table 2. Antibiotics sensitivity of bacteria before and after exposure to microwave radiation

\begin{tabular}{|c|c|c|c|c|c|c|c|c|}
\hline & \multicolumn{2}{|c|}{ Chloramphenicol } & \multicolumn{2}{c|}{ Cefixime } & \multicolumn{2}{c|}{ Ciprofloxacin } & \multicolumn{2}{c|}{ Amoxicillin } \\
\hline & $\begin{array}{c}S . \\
\text { aureus }\end{array}$ & $\begin{array}{c}E . \\
\text { coli }\end{array}$ & $\begin{array}{c}S . \\
\text { aureus }\end{array}$ & $\begin{array}{c}E . \\
\text { coli }\end{array}$ & $\begin{array}{c}S . \\
\text { aureus }\end{array}$ & $\begin{array}{c}E . \\
\text { coli }\end{array}$ & $\begin{array}{c}S . \\
\text { aureus }\end{array}$ & $\begin{array}{c}E . \\
\text { coli }\end{array}$ \\
\hline Control & 15 & 23 & 25 & 22 & 43 & 34 & 8 & 28 \\
\hline $\begin{array}{c}\text { Exposed } \\
\text { for 2 min }\end{array}$ & 16 & 18 & 24 & 25 & 29 & 30 & 5 & 22 \\
\hline $\begin{array}{c}\text { Exposed } \\
\text { for 3 min }\end{array}$ & 9 & 12 & 10 & 20 & 25 & 23 & 38 & 8 \\
\hline
\end{tabular}
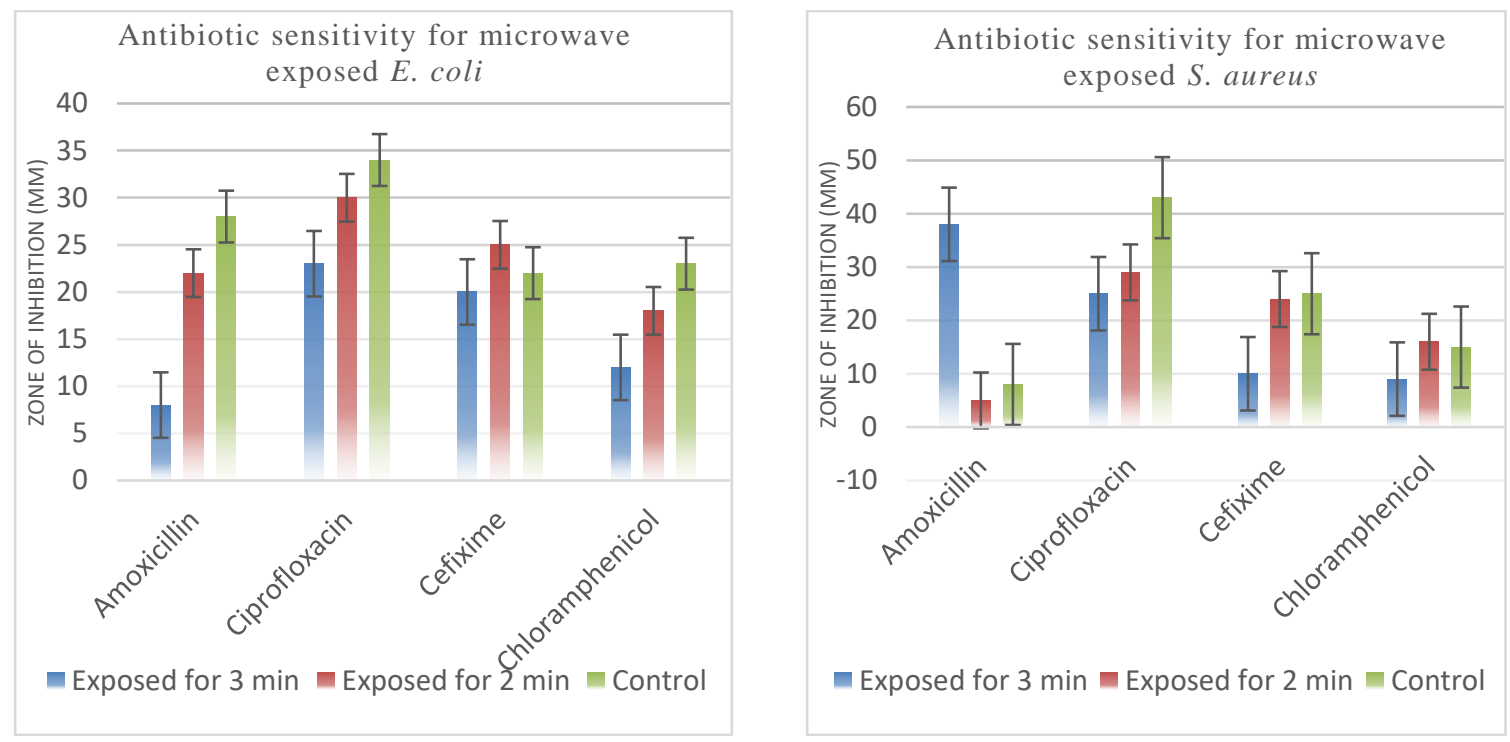

Figure 1. Antibiotic Sensitivity for Microwave exposed bacteria and control

\section{Discussion}

This study indicated that MR reported to have better effect in thermal phase, compared to nonthermal phase as presented in table 1 which presents that $E$. coli was more sensitive to MR than $S$. aureus. Gram-positive bacteria were characterized with strong peptidoglycan layer in their cell wall, which may partially protect $S$. aureus from MR. However, the best destruction time was noted to be 2 and $3 \mathrm{~min}$ for gram negative and only $3 \mathrm{~min}$ for gram positive which supports the hypothesis. Previous study has reported that $110 \mathrm{sec}$ (less than $2 \mathrm{~min}$ ) exposure to thermal MR was enough to deactivate $S$. aureus. This may justify that the killing of bacteria took place due to heat transfer and its direct effect on cells (Almshgab, Yahya, \& Banu, 2020, Liu, 2014). Other studies reported that the effect of MR on $S$. aureus bacteria varies from killing to enhancing or slowing their growth (Mahdi \& Gomes, 2019). The thermal effect of MR is manifested as the elevation of system temperature by passing of waves through it. This is accompanied by different physiological and biological effects, which may be attributed to cell wall disturbance and leakage of cell contents (Woo, Rhee, \& Park, 2000). Similarly, in a study done by Jagani et al., (2012) both tested microorganisms like this study were also destroyed and deactivated after being exposed to MR for 3 $\min$.

Non-thermal MR was able to cause changes in the microbial growth of both tested organisms on at least two occasions (table 1). According to Rosario, Rodrigues, Bernardes, \& Conte-Junior, (2020) reported that not much is known about the exact mechanisms of the effect of non-thermal MR, as the publications regarding this is limited in number. However, in a study done by Shamis et al., 
(2011) which is similar in methods to the current study. E. coli suspension was exposed to MR and temperature remained below $40^{\circ} \mathrm{C}$. When the treated cell examined under electron microscope $20 \mathrm{~nm}$ in diameter pores in cell wall was observed, it allowed the passage of dextran molecules, leading to the dehydration of cells. However, in the current study there is no big difference that can be observed among non-thermal effect of MR between gram positive and gram-negative selected bacteria. However, there is a noticeable difference in time of exposure. The $3 \mathrm{~min}$ exposure to non-thermal MR was able to dramatically minimize the number of both microorganisms. Such elimination could not be credited to the elevation of temperature (thermal effect) because the temperature was maintained around room temperature. According to Tahir, Mateen, Univerdi, KaraGoban, \& Zengin (2009), the same temperature from different other sources was tested and did not give similar changes as non-thermal MR.

Regarding antibiotic resistance mutagenesis effect of MR, Edwards (2012) reported that vitro exposure of microorganisms to MR accelerated the synthesis machinery of many molecules such as glycol-peptides which may increase antibiotic resistance. As showed in table 2 and figure 1, the results of this study indicate that the control strains of both $S$. aureus and E. coli were sensitive to the four common antibiotics except for $S$. aureus to Amoxicillin. Surprisingly, the bacterial resistance is highly developed by prolonged exposure time $(3 \mathrm{~min})$. The present study gives details that exposure to MR may affect Bacteria plasmid to enhance bacterial resistance. Thus, long exposure time may cause adverse mutation leading to reverse bacterial sensitivity, as shown in fig. 1. These results are similar to the study of I. Said-Salman, F. Jebaii, H. Yusef, \& M. Moustafa, (2019) which conclude that bacterial exposure to Wi-Fi microwave leads to increase antibiotic resistance and motility of $E$. coli and $S$. aureus. Electromagnetic fields and mobile tower radiations have been reported in gaining antibiotic resistance. That can significantly alter the vital systems in microbes and turn them multidrug resistant (MDR), which is important as current threat to public health (I. Said-Salman et al., 2019; Sharma, Lamba, Sharma, \& Sharma, 2018). This confirms the results obtained from this study. However, in the study of El-Guendouz et al., (2018), it is reported that microbial exposure to MR has no significant effect in resistance to certain antibiotics. S. aureus - treated with amoxicillin $(30 \mu \mathrm{g})$, exposed to electromagnetic fields, and radiation treatment - had no significant effect on bacterial sensitivity to antibiotics. Similarly, Ogunniran, David, Isinkaye, \& Olawale (2019) have reported that gamma radiation reduced the population of Enterococcus faecalis and Escherichia coli in water, but does not positively affect their susceptibility to antibiotics. Furthermore, Zhao, Hu, Ren, \& Zhang (2018) conducted study on the changing patterns of antibiotic susceptibility of the surviving $P$. aeruginosa after UV disinfection. Antibiotic susceptibility tests indicated that the surviving $P$. aeruginosa seemed more susceptible to norfloxacin, carbenicillin, rifampicin, vancomycin and chloromycetin after UV irradiation. A direct comparison of the current study may be difficult because of the differences of experimental procedures employed and the differences in the bacterial strains. S. aureus become highly sensitive to Amoxicillin opposed to other tested antibiotics. This may be caused by the disturbance of bacterial cell wall by MR and formation of pores, as explained earlier (Shamis et al., 2011).

\section{Conclusion}

Based on the results obtained, it is safe to conclude that microwave oven is an effective tool to use for heating and cooking food, as it effectively eliminates the numbers of each of $E$. coli and of $S$. aureus bacteria. Therefore, it prevents food poisoning caused by such bacteria. However, the present study recommends reducing the use of microwave ovens. It also recommends that more studies on 
other Bacterial strains are needed to confirm microwave's altering effect to convert bacteria to be more resistant. Moreover, the use of microwave oven causes DNA mutagen effect, which possibly may be an additional reason for the outbreak of antibiotic resistant organisms.

\section{Acknowledgement}

The author(s) of this work received no financial support for the authorship and/or publication of this article.

\section{References.}

[1] Alharbi, S. A., Salmen, S. H., Chinnathambi, A., Alharbi, N. S., Zayed, M., Al-Johny, B. O., \& Wainwright, M. (2016). Assessment of the bacterial contamination of hand air dryer in washrooms. Saudi journal of biological sciences, 23(2), 268-271.

[2] Almashgab, A. M., Yahya, E. B., \& Banu, A. (2020). The Cytotoxicity Effects of Outer Membrane Vesicles Isolated from Hospital and Laboratory Strains of Pseudomonas Aeruginosa on Human Keratinocyte Cell Line. Malaysian Journal of Science, 45-53.

[3] Banik, S., Bandyopadhyay, S., \& Ganguly, S. (2003). Bioeffects of microwave-a brief review. Bioresource technology, 87(2), 155-159.

[4] Biagi, M. C., Fabregas, R., Gramse, G., Van Der Hofstadt, M., Juárez, A., Kienberger, F., . . Gomila, G. (2016). Nanoscale electric permittivity of single bacterial cells at gigahertz frequencies by scanning microwave microscopy. ACS nano, 10(1), 280-288 .

[5] Cohen, R., \& Wald, P. H. (2016). MICROWAVE, RADIOFREQUENCY, and EXTREMELY LOWFREQUENCY ENERGY. Physical and Biological Hazards of the Workplace, 215-221 .

[6] Edwards, G. A. (2012). Consumer and processor methods to control Salmonella and Listeria in shrimp .

[7] El-Guendouz, S., Aazza, S., Lyoussi, B., Bankova, V., Popova, M., Neto, L., . . Miguel, M. d. G. (2018). Moroccan propolis: A natural antioxidant, antibacterial, and antibiofilm against Staphylococcus aureus with no induction of resistance after continuous exposure. Evidence-Based Complementary and Alternative Medicine, 2018 .

[8] Jagani, C. L., Sojitra, N. A., Vanparia, S. F., Patel ,T. S., Dixit, R. B., \& Dixit, B. C. (2012). Microwave promoted synthesis and antimicrobial activity of 3-thiazole substituted 2-styryl-4 (3H)-quinazolinone derivatives. Journal of Saudi Chemical Society, 16(4), 363-369 .

[9] Kang, Y., \& Kato, S. (2014). Thermal and non-thermal germicidal effects of microwave radiation on microbial agents. Indoor and Built Environment, 23(8), 1080-1091 .

[10] Liu, X. (2014). UV and Visible Light Active Nanostructure Photocatalysts for Disinfection and Decomposition of Biohazards .

[11] Ma, Z., Bumunang, E. W., Stanford, K., Bie, X., Niu, Y. D., \& McAllister, T. A. (2019). Biofilm formation by shiga toxin-producing Escherichia coli on stainless steel coupons as affected by temperature and incubation time. Microorganisms, 7(4), 95 .

[12] Mahdi ,A., \& Gomes, C. (2019). Effects of microwave radiation on micro-organisms in selected materials from healthcare waste. International Journal of Environmental Science and Technology, 16(3), 1277-1288 .

[13] Mazinani, S. (2019). Investigation of the effect of microwave irradiation $(2.45 \mathrm{GHz})$ on biological systems at constant bulk temperature .

[14] Ogunniran, A., David, O., Isinkaye, M., \& Olawale, A. (2019). Effects of sub-lethal gamma irradiation on antibiotic susceptibility profile and population dynamics of Enterococcus faecalis and Escherichia coli in water. Sri Lanka Journal of Aquatic Sciences, 24 .(1)

[15] Patel, P., Patel, H., Vekariya, D., Joshi, C., Patel, P., Muskal, S., \& Kothari, V. (2019). Sonic Stimulation and Low Power Microwave Radiation Can Modulate Bacterial Virulence Towards Caenorhabditis elegans. Anti-Infective Agents, 17(2), 150-162 .

[16] Qiao, M., Ying, G.-G., Singer, A. C., \& Zhu, Y.-G. (2018). Review of antibiotic resistance in China and its environment. Environment international, 110, 160-172. 
[17] Rosario, D. K., Rodrigues, B. L., Bernardes, P. C., \& Conte-Junior, C. A. (2020). Principles and applications of non-thermal technologies and alternative chemical compounds in meat and fish. Critical Reviews in Food Science and Nutrition, 1-21 .

[18] Said-Salman, I., Jebaii, F., Yusef, H., \& Moustafa, M. (2019). Evaluation of Wi-Fi Radiation Effects on Antibiotic Susceptibility, Metabolic Activity and Biofilm Formation by Escherichia Coli 0157H7, Staphylococcus Aureus and Staphylococcus Epidermis. Journal of Biomedical Physics and Engineering, 9(5), 579-586 .

[19] Said-Salman, I. H., Jebaii, F. A., Yusef, H. H., \& Moustafa, M. E. (2019). Global gene expression analysis of Escherichia coli K-12 DH5 $\alpha$ after exposure to $2.4 \mathrm{GHz}$ wireless fidelity radiation. Scientific reports, 9(1), 1-10

[20] Shamis, Y., Taube, A., Mitik-Dineva, N., Croft, R., Crawford, R. J., \& Ivanova, E. P. (2011). Specific electromagnetic effects of microwave radiation on Escherichia coli. Applied and Environmental Microbiology, 77(9), 3017-3022 .

[21] Sharma, A. B., Lamba, O., Sharma, L., \& Sharma, A. (2018). Effect of Mobile Tower Radiation on Microbial Diversity in Soil and Antibiotic Resistance. Paper presented at the 2018 International Conference on Power Energy, Environment and Intelligent Control (PEEIC.(

[22] Tahir, A., Mateen, B., Univerdi, S., KaraGoban, O., \& Zengin, M. (2009). Simple method to study the mechanism of thermal and non thermal bactericidal action of microwave radiations on different bacterial species. African Journal of Bacteriology Research, 1(5), 058-063 .

[23] Wilbur, K., \& Al Tawengi, K. (2016). A Systematic Review of Metformin Therapy and Renal Outcomes in Type 2 Diabetes Mellitus. Journal of Endocrinology and Diabetes Mellitus, 4(1), 1-9 .

[24] Woo, I.-S., Rhee, I.-K., \& Park, H.-D. (2000). Differential damage in bacterial cells by microwave radiation on the basis of cell wall structure. Applied and Environmental Microbiology, 66(5), 2243-2247 .

[25] Yahya, E., \& Abdulsamad, M. A. (2020). In-vitro Antibacterial Activity of Carbopol-Essential Oils hydrogels. Journal of Applied Science \& Process Engineering, 7(2), 564-571 .

[26] Yahya, E. B., Alhawari, S. M., Amhimmid, K., AbuAeshah, R. H. A., \& Saada, A. O. (2018). EVALUATION OF IN-VITROANTIBACTERIAL ACTIVITY OF AQUEOUS AND ALCOHOLIC EXTRACTS OF THE PEELS PUNICA GRANATUM AND OLEA EUROPAEA LEAVES. Journal of Sciences and Technologies (Medical Science), 2 .(1)

[27] Yahya, E. B., Jummaat, F., Amirul, A., Adnan, A., Olaiya, N., Abdullah, C., . . Khalil, H. (2020). A review on revolutionary natural biopolymer-based aerogels for antibacterial delivery. Antibiotics, 9(10), 648 .

[28] Zhao, F., Hu, Q., Ren, H., \& Zhang, X.-X. (2018). Ultraviolet irradiation sensitizes Pseudomonas aeruginosa PAO1 to multiple antibiotics. Environmental Science: Water Research \& Technology, 4(12), 2051-2057 . 